Available online on 15.01 .2020 at http://jddtonline.info
Open Access to Pharmaceutical and Medical Research
unrestricted non-commercial use, provided the original work is properly cited

Open@ Access

Research Article

\title{
Development and Validation of Stability Indicating RP-HPLC Method for Estimation of Cilnidipine
}

\author{
Tiwari Balakrishna ${ }^{*}$, Shirsat Mrunal K.2, Kulkarni Amol ${ }^{3}$ \\ 1 Research Scholar, Pacific University, Udaipur, India \\ 2 Dean/Principal, PAHER University, Udaipur, India \\ 3 Director, Institute of Pharmaceutical Science and Research (for girls), Swami Chincholi, Daund, Maharashtra, India
}

\begin{abstract}
Cilnidipine is one of the dihydropyridine calcium antagonists. It was created combinedly by Fuji Viscera Pharmaceutical Company, Ajinomoto and Japan and was approved in the year 1995. Cilnidipine acts on N-type calcium channel where exist the end of sympathetic nerve in addition to common L-type calcium channel like that of other calcium antagonists. China, Japan, India, Korea and several other countries approved this drug. The objective of the method validation is to demonstrate whether the method was suited for the intended purpose. The method was validated as per the ICH guidelines. The method was validated for linearity, precision (repeatability, intermediate precision), accuracy, specificity, robustness, limit of detection and limit of quantification. Cosmosil ( 4.6 X 250mm, $5 \mu$ ) column was used for separation. The selected wavelength for Cilnidipine was $241 \mathrm{~nm}$. The mobile phase consists Methanol: Potassium dihydrogen phosphate buffer (50:50). Flow rate was delivered at $1.0 \mathrm{~mL} / \mathrm{min}$. Appropriate dilutions of standard stock solutions were prepared as per the get desired concentrations in the range of $100-500 \mathrm{mcg} / \mathrm{ml}$. The RT obtained was 4.8165 minutes.
\end{abstract}

Keywords: Cilnidipine, UV spectroscopy, RP-HPLC, ICH

Article Info: Received 10 Nov 2019; Review Completed 25 Dec 2019; $\quad$ Accepted 04 Jan $2019 ; \quad$ Available online 15 Jan 2020

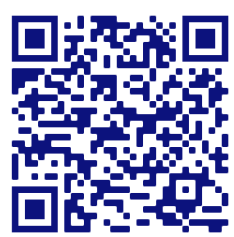

Cite this article as:

Tiwari B, Shirsat M K, Kulkarni A, Development and Validation of Stability Indicating RP-HPLC Method for Estimation of Cilnidipine, Journal of Drug Delivery and Therapeutics. 2020; 10(1):97-100 http://dx.doi.org/10.22270/jddt.v10i1.3846

*Address for Correspondence:

Tiwari Balakrishna, Research Scholar, Pacific University, Udaipur, India

\section{INTRODUCTION:}

Cilnidipine is one of the dihydropyridine calcium antagonists. It was created combinedly by Fuji Viscera Pharmaceutical Company, Ajinomoto and Japan and was approved in the year 1995. Cilnidipine acts on N-type calcium channel where exist the end of sympathetic nerve in addition to common L-type calcium channel like that of other calcium antagonists. China, Japan, India, Korea and several other countries approved this drug. ${ }^{1}$

IUPAC nomenclature: 3-(2-methoxyethyl) 5-(2E)-3phenylprop-2-en-1-yl 2,6-dimethyl-4-(3-nitrophenyl)-1,4dihydropyridine-3,5-dicarboxylate

Literature review suggest few RP-HPLC, HPTLC, spectroscopic, stability indicating HPLC determinations were performed. ${ }^{2-15}$ The aim of the present study is to develop a simple, precise, accurate, sensitive HPLC method for the determination. After, doing in depth study in the present research work, it was found that the present research work is having various advantages over the previous work. The advantages include less retention times of the component, with good resolution. The \% RSD of robustness was found to be less. The results obtained from the validation suggest that the method was found to be precise, accurate, linear and robust enough and the method was also found to be economical.<smiles>COCCOC(=O)C1=C(C)NC(C)=C(C(=O)OC/C=C/c2ccccc2)C1c1cccc([N+](=O)[O-])c1</smiles>

Figure 1: Structure of Cilnidipine 


\section{EXPERIMENTAL WORK:}

Chemicals and reagents: HPLC grade acetonitrile, methanol, from Spectro Chemie. Ammonium acetate, acetic acid of analytical grade was used. Millipore grade water was used. The reference standard samples of Cilnidipine was provided was provided by Ajanta Pharma.

\section{Instrumentation and analytical conditions:}

The analysis was carried out by using Younglin (S.K) Gradient System UV Detector, 4.6X250mm cosmosil column, $20 \mathrm{ml}$ loop size HPLC (With UV/Vis Detector. Other instrumentation includes Double beam UV- Visible spectrophotometer Simadzu UV-1800, digital balance (metler tolado), vacuum pump (Gelman science), pH meter (poloman).

\section{Chromatographic conditions:}

Cosmosil (4.6X250mm, $5 \mu$ ) column was used for separation. Methanol: Potassium dihydrogen phosphate buffer (50:50) was the optimized mobile phase.

\section{Preparation of Standard stock solution:}

$100 \mathrm{mg}$ of Cilnidipine was weighed in to $100 \mathrm{ml}$ volumetric flasks. The drug was dissolved in $40 \mathrm{ml}$ of solvent, and shaken manually for $10 \mathrm{~min}$. The volume was made up to the mark with solvent and the final strength obtained was 1000 $\mu \mathrm{g} / \mathrm{ml}$.

\section{Preparation of Working Standard Solutions:}

$10 \mathrm{ml}$ of the standard stock solution of Cilnidipine was pipette out in to $100 \mathrm{ml}$ volumetric flasks and the volume was made up to the mark with solvent, and the final strength obtained was $100 \mu \mathrm{g} / \mathrm{ml}$.

\section{Validation procedure:}

Method validation has the objective of establishing the suitability of any method for the experimental purposes. Method validation are carried out as per the ICH guidelines. Linearity, precision (repeatability, intermediate precision), accuracy, specificity, robustness, limit of detection and limit of quantification were checked in the method validation. A calibration curve was constructed by taking six different concentrations. The peak area was calculated, and calibration curve was constructed by taking peak area and concentration on both the axis. The linearity was evaluated by linear regression analysis. The precision studies were demonstrated by two parameters inter day and intraday precision. Intraday precision was performed by injecting six replicated injections to the chromatographic system on the same day and calculated the \%RSD. The inter day precision was performed by injecting six replicated injections at two consecutive days. From the peak area of the chromatograms, the \%RSD was calculated. The accuracy was determined by adding a known amount of the standard to the sample, and the percentage recovery was estimated. The robustness was determined by incorporating deliberate changes into the method conditions like the change in flow rate, $\mathrm{pH}$, and gradient.

\section{RESULTS AND DISCUSSION:}

\section{Selection of wavelength:}

UV spectrum was obtained by preparing a solution by taking diluents and scanned between 200 to $400 \mathrm{~nm}$. Brinzolamide shows $\lambda_{\max }$ at $241 \mathrm{~nm}$. So, it is selected as a detection wavelength.

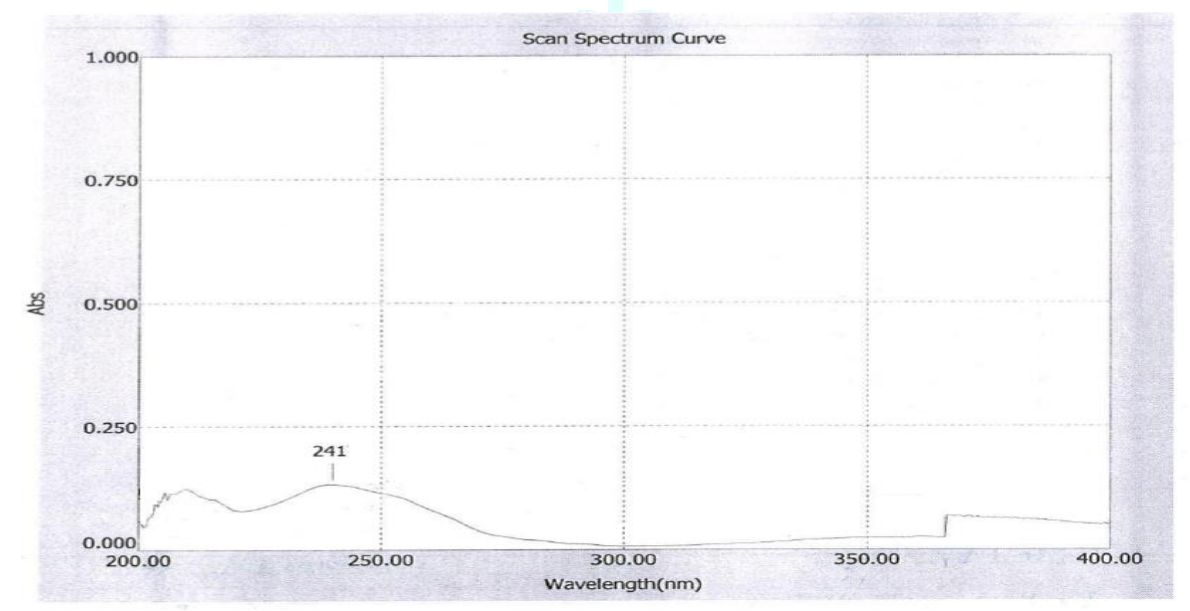

Figure 2: Spectrum of Cilnidipine

Standard curve of Cilnidipine:

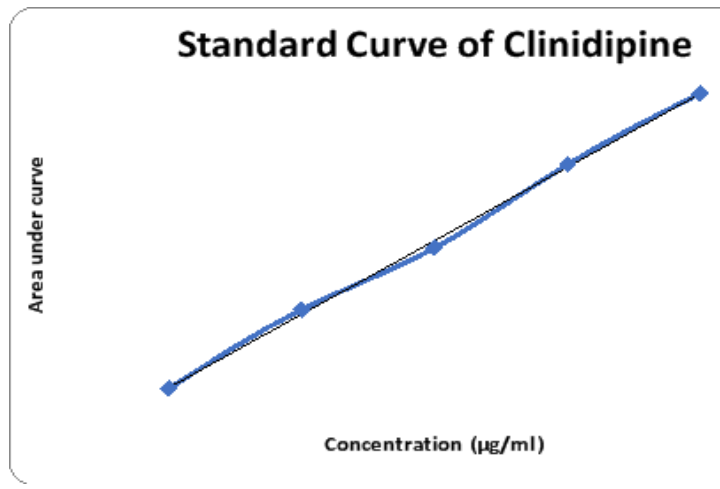

Figure 3: Standard curve of Cilnidipine 


\section{Development and optimization of the HPLC method:}

For getting an optimized chromatographic condition, A Cosmosil (4.6X250mm, $5 \mu$ ) column was used for separation. The mobile phase consists of Methanol: Potassium dihydrogen phosphate buffer (50:50). Flow rate was delivered at $1.0 \mathrm{~mL} / \mathrm{min}$ with detection wavelength at 241 nm. $20 \mu \mathrm{L}$ was injected to the chromatographic system with ambient temperature. The RT obtained was 4.8165 minutes.

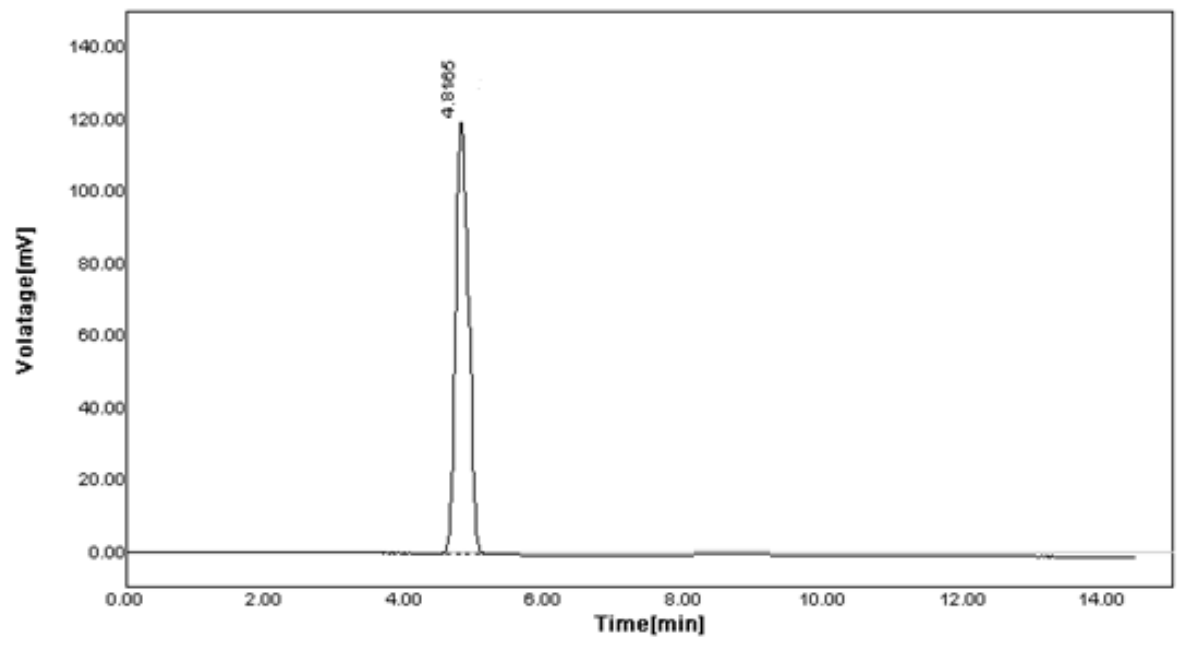

Figure 4: RT of Brinzolamide

\section{Method validation:}

\section{Linearity:}

Appropriate dilutions of standard stock solutions were prepared to get desired concentrations in the range of $100-500 \mathrm{mcg} / \mathrm{ml}$. Then the concentrations were plotted against the area under curves to get the equation of standard curve, as presented in Table 1.

Table 1: Dilutions for linearity study

\begin{tabular}{|c|c|c|}
\hline Stock solution $(\boldsymbol{\mu l})$ & Diluted $(\mathbf{m l})$ & Final concentration \\
\hline 100 & 10 & 10 \\
\hline 200 & 10 & 20 \\
\hline 300 & 10 & 30 \\
\hline 400 & 10 & 40 \\
\hline 500 & 10 & 50 \\
\hline
\end{tabular}

\section{Precision:}

Precision is determined at two levels: a) Repeatbility b) Intraday and Interday Precision.

Table 3: Precision Data

\begin{tabular}{|l|l|l|l|}
\hline Parameter & Amount taken $(\boldsymbol{\mu g} / \mathbf{m l})$ & Amount found $(\boldsymbol{\mu g} / \mathbf{m l})$ & \%RSD \\
\hline System Precision & 60 & 59.91 & 0.681 \\
\hline Method Precision & 60 & 60.12 & 0.592 \\
\hline
\end{tabular}

${ }^{*}$ Mean of Six observations

Table 4: Intraday and Interday Precision Data

\begin{tabular}{|l|l|l|l|l|}
\hline Concentration of Brinzolamide & Intraday* & \%RSD & Interday * & \%RSD \\
\hline $20 \mu \mathrm{g} / \mathrm{ml}$ & 20.09 & 0.118 & 19.92 & 0.249 \\
\hline $40 \mu \mathrm{g} / \mathrm{ml}$ & 39.92 & 0.132 & 39.94 & 0.362 \\
\hline $60 \mu \mathrm{g} / \mathrm{ml}$ & 60.13 & 0.209 & 59.91 & 0.419 \\
\hline
\end{tabular}

*Mean of three observations 


\section{Accuracy:}

To check the accuracy of the developed methods, analytical recovery experiment was carried out by standard addition method. Recovery study was performed by adding 80, 100 and $120 \%$ of the test concentration as per ICH guidelines.

Table 5: Accuracy

\begin{tabular}{|c|c|c|c|}
\hline $\begin{array}{c}\text { Sr. } \\
\text { No. }\end{array}$ & $\begin{array}{c}\text { Concentration } \\
\text { of Drug Added } \\
(\boldsymbol{\mu g} / \mathbf{m l})\end{array}$ & $\begin{array}{c}\text { Concentration } \\
\text { of Drug Added } \\
(\boldsymbol{\mu g} / \mathbf{m l})\end{array}$ & $\begin{array}{c}\mathbf{\%} \\
\text { Recovery } \mathbf{\pm} \\
\text { SD }\end{array}$ \\
\hline $\mathbf{1}$ & 64 & 10.4 & $99.99 \pm 0.182$ \\
\hline $\mathbf{2}$ & 80 & 13 & $99.82 \pm 0.273$ \\
\hline $\mathbf{3}$ & 96 & 15.6 & $98.77 \pm 0.317$ \\
\hline
\end{tabular}

\section{Limit of Quantification (LOQ) and Limit of Detection (LOD):}

The limit of quantification (LOQ) is defined as the lower concentration of an analyte in a sample that can be determined with acceptable precision and accuracy under the stated operational conditions of the method. The limit of detection (LOD) is defined as the lowest concentration of an analyte in a sample that can be detected, not quantified. The LOD and LOQ were estimated from the set of 5 calibration curves used to determine method linearity. The LOD and LOQ were calculated using formula given below.

$$
\mathrm{LOD}=3.3 \times \sigma / \mathrm{S}
$$

$\mathrm{LOQ}=10 \times \sigma / \mathrm{S}$

Where, $\sigma=$ Standard deviation of the Y- intercepts of the 5 calibration curves, $\mathrm{S}=$ Mean slope of the 5 calibration curves. The LOQ and LOD parameters of Brinzolamide are provided in Table 6.

Table 6: LOD and LOQ parameters

\begin{tabular}{|l|l|}
\hline Parameter & Values \\
\hline S.D. of Intercept* & 0.6148 \\
\hline Mean Slope of Calibration Curve* & 430.79 \\
\hline LOD $(\mu \mathrm{g} / \mathrm{ml})$ & 0.00471 \\
\hline LOQ $(\mu \mathrm{g} / \mathrm{ml})$ & 0.01427 \\
\hline
\end{tabular}

\section{Robustness:}

Robustness was studied by observing the change in following parameters, and then observation of each parameter change was done to access their effect on system suitability and assay. Change in mobile phase composition was done by $\pm 5.0 \mathrm{ml}$ of organic solvent and the change in the detection wavelength $\pm 10 \mathrm{~nm}$ was done.

Change in mobile phase composition: The sample solution at test concentration $(60 \mu \mathrm{g} / \mathrm{ml}$ of drug was injected thrice with the mobile phase composition changed by $\pm 5.0 \mathrm{ml}$ of organic solvent from the developed method.

Change in detection wavelength: The sample solution at test concentration $(60 \mu \mathrm{g} / \mathrm{ml}$ of drug was injected thrice with the change in detection wavelength by $\pm 10 \mathrm{~nm}$ from the developed method. The \% assay of drug after changes in method parameters were observed.

\section{CONCLUSION:}

A precise RP - HPLC method was developed for the determination of Brinzolamide. The shorter run time elutes Erlotinib hydrochloride with good resolution, and symmetry. The method was validated as per the ICH guidelines and the method was found to be simple, precise, linear, accurate, rugged and robust enough.

Table 7: Summary of Validation parameters

\begin{tabular}{|l|l|}
\hline Parameters & Cilnidipine \\
\hline Accuracy & $98.77 \pm 0.317-99.99 \pm 0.182$ \\
\hline Precision (\%RSD) \\
\hline System Precision & 0.681 \\
\hline Method Precision & 0.592 \\
\hline Intra-day (n = 3) & $0.118-0.209$ \\
\hline Inter-day (n = 3) & $0.249-0.419$ \\
\hline LOD and LOQ & 0.00471 \\
\hline LOD & 0.01427 \\
\hline LOQ
\end{tabular}

\section{REFERENCES:}

1. Cilnidipine. https://www.drugbank.ca/drugs/DB09232.

2. Kudumula, N.; Prasad Rajendra, Y. Development and Validation of RP-HPLC Method for the Simultaneous Estimation of Chlorthalidone and Cilnidipine in Bulk and Combined Tablet Dosage Form. Pharmacophore 2014, 5 (4), 442-450.

3. Mital, J. S.; Patel, B.; Biosci, A. P.-I. J. P.; 2014, U. Development and Validation of RP-HPLC Method for Simultaneous Estimation of Cilnidipine and Olmesartan Medoxomil in Their Combined Tablet Dosage Form. Int. J. Pharm. Biol. Sci. 2014, 4 (1), 157-160.

4. Rupareliya, R.; Joshi, H. Stability Indicating Simultaneous Validation of Telmisartan and Cilnidipine with Forced Degradation Behavior Study by RP-HPLC in Tablet Dosage Form. ISRN Chromatogr. 2013, 1-6.

5. Safhi, M.; Nagaraj, M. Development and Validation of a Rapid Stability Indicating Chromatographic Determination of Cilnidipine in Bulk and Dosage Form. Res. J. Pharm. Tech. 2013, 6 (3), 296299.

6. Wankhede, S. B.; Bhole, R. p. Development and Validation of HPTLC Method for Simultaneous Estimation Of Cilnidipine And Valsartan In Bulk And Tablet Dosage Form. Int. J. Pharm. Chem. Anal. 2015, 2 (1), 102-107.

7. Patel, P. R.; Patel, N.; Shah, S. K. Analytical Method Development and Validation for Simultaneous Estimation of Nebivolol Hydrochloride and Cilnidipine in Combined Dosage Form. J. Chem. Pharm. Res. 2015, 7 (9), 951-960.

8. Ravi Sankar, P.; Swathi, V. Development and Validation Of Novel UV And RP-HPLC Methods For Determination Of Cilnidipine (A New Generation Ca Channel Blocker) In Pharmaceutical Dosage Form. Int. J. Pharm. Sci. Res. 2019, 10 (4), 1886-1894. https://doi.org/10.13040/IJPSR.0975-8232.10(4).1886-94.

9. Patel, B.; Chaudhary, A. Development and Validation of Reversed Phase High Performance Liquid Chromatography Method for Simultaneous Estimation of Nebivolol $\mathrm{HCl}$ and Cilnidipine In. Pharm. Biol. Eval. 2016, 3 (2), 208-214.

10. Dagariya, R.; Jat, R. Method Development and Validation of Irbesartan Chlorthalidone and Cilnidipine in Their Combined Tablet Dosage Form by High Performance Liquid Chromatography. J. Drug Deliv. Ther. 2017, 7 (4), 88-96.

11. Soni, I.; Panchal, H. Development and Validation of Dual Wavelength UV Spectrophotometric Method for Simultaneous Estimation of Cilnidipine and Olmesartan Medoxomil In. Indian J. Pharm. Biol. Res. 2014, 2 (1), 76-81.

12. Patel, S.; Hinge, M.; Bhanushali, V. Development and Validation of an UV Spectrophotometric Method for Simultaneous Determination of Cilnidipine and Chlorthalidone. J. Pharm. Res. 2015, 9 (1), 41-45.

13. Kachave, R.; Kale, M.; Wagh, R. Simultaneous Estimation of Cilnidipine and Valsartan by RP-HPLC in Tablet Formulation. Eurasian J. Anal. Chem. 2016, 11 (5), 245-253.

14. Desai, D.; Vashi, N.; Dalvadi, H. HPTLC Method Development and Validation of Cilnidipine and Metoprolol Succinate in Combined Dosage Form. Pharma methods 2016, 7 (1), 28-34.

15. Haripriya, M.; Antony, N.; Jayasekhar, P. Development and Validation of UV Spectrophotometric Method for the Simultaneous Estimation of Cilnidipine and Telmisartan in Tablet Dosage Form Utilising. Int. J. Pharm. Biol. Sci. 2013, 3 (1), 343-348. 